\title{
"Validación del mucílago de café para la producción de etanol y abono orgánico"
}

\author{
Sandra Blandón - Docente Universitaria • Bayardo Castillo / Ana Llancys López - Tesistas
}

\section{Resumen}

La investigación contó con el apoyo técnico y financiero de la Fundación para el Desarrollo Tecnológico Agropecuario y Forestal de Nicaragua (FUNICA) y su finalidad fue validar el mucílago de café para la obtención de etanol y abono orgánico, como una alternativa para disminuir la contaminación de fuentes de agua en la zona norte de Nicaragua. La elaboración de etanol se efectuó en el laboratorio de agroindustria de la UNI, sede Regional del Norte en dos periodos, Enero a Marzo del 2011 y de Enero a Abril del 2012, respectivamente. Para la validación del etanol se realizó recolección del mucílago fresco y fermentado aplicando la técnica de lavado manual, utilizando 1 litro de agua para 10 libras de café. En el primer período del estudio se obtuvieron valores de 3 y 5 grados Brix, y en el segundo período de 8 y 10 grados Brix. Los análisis bromatológicos del mucílago fresco y fermentado señalan que los porcentajes de carbohidratos, cenizas, proteínas, humedad son superiores a los presentados por el Investigador Nelson Rodríguez, sin embargo los rendimientos de alcohol obtenidos durante el estudio fueron inferiores en ambos períodos, $2 \%$ y $0.40 \%$, lo que no apoya el uso del mucílago del café en la producción de alcohol. Con el mucílago residual del destilado se elaboró abono orgánico líquido sustituyendo el agua de la formulación inicial por mucílago. Se empleó $2.06 \%$ de leguminosa, $6.23 \%$ de estiércol fresco de bovino y $91.70 \%$ de mucílago. La mezcla se fermentó anaeróbicamente durante 15 días. Después, se extrajeron muestras y se determinaron promedios de Nitrógeno $0.85 \%$, fósforo $0.0094 \%$ y potasio $0.018 \%$. Por otra parte, el nitrógeno presente en este abono, explica que el producto pueda ser utilizado como inductor del crecimiento, indicando que este producto se encuentra en una escala intermedia con respecto a la calidad del abono comercial. De los resultados de la experimentación se obtuvo que las dosis del $10 \%$ y $30 \%$ de abono orgánico a partir de mucílago de café sea una alternativa para la agricultura, por lo tanto aumentando el porcentaje de aplicación se podrían mejorar los resultados. Al analizar los costos de producción se demostró que el abono orgánico tiene un costo menor que el comprar fertilizante líquido comercial y por lo tanto, el productor se ahorraría C\$ 269 por ciclo vegetativo en una manzana de plantas de tomate.

Palabras Clave: mucílago de café, abono orgánico, etanol, beneficio de café.

\section{Introducción}

La presente investigación contó con el apoyo técnico y financiero de FUNICA, en el marco del proyecto "Desarrollo de productos a partir de los desechos del café y validación de pequeñas estructuras de beneficio húmedo", de la alianza UNI FUNICA.

Para el desarrollo del estudio se tomó en cuenta que el creciente número de beneficios húmedos de café en Nicaragua y el incremento en la producción de este rubro genera grandes cantidades de residuos orgánicos con alto potencial contaminante, entre ellos están el mucílago, la pulpa y las aguas residuales, las que son vertidas de manera directa en los ríos y terrenos superficiales cercanos al beneficio.

El grano de café recién despulpado está recubierto de una capa mucilaginosa (Mesocarpio), que es 15.5 a $22 \%$ del peso del fruto maduro con relación al contenido de humedad. El mucílago es una estructura rica en azúcares y pectinas que cubre el endospermo de la semilla y mide aproximadamente 0.4 milímetros de espesor (ANACAFE, 2005). 
Tomando en cuenta lo anterior, se propuso la realización dela presente investigación, la cual requirió de la alianza con productores para visitar beneficios húmedos y recolectar muestras. Además fue necesario determinar las características del mucílago y la elaboración de productos (etanol y abono orgánico) para disminuir el impacto de los desechos orgánicos originados en los beneficios húmedos, siendo esta una alternativa medioambiental y económica para las zonas cafetaleras del país.

\section{Materiales y métodos}

El estudio sobre la producción de etanol se llevó a cabo en el laboratorio de Agroindustria de la UNI Sede Regional del Norte. Las pruebas con el abono orgánico se realizaron en el invernadero de la misma universidad.

Realización de análisis para el mucílago de café

Entre los parámetros que se midieron en el laboratorio de Agroindustria se tienen el $\mathrm{pH}$, que fue medido con cintas de papel $\mathrm{pH}$, y los grados Brix, que se midieron con un refractómetro.

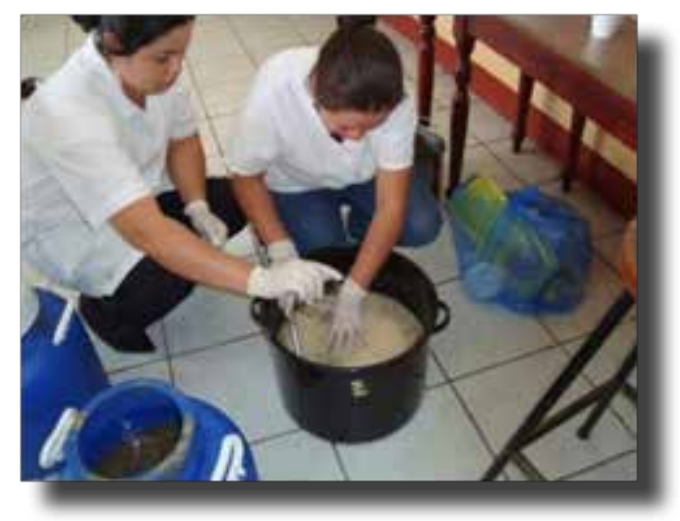

Figura 1. Medición de pH y grados Brix del Mucílago

Producción de materia prima para elaborar etanol

El mucílago de café se recolectó en fincas que presentaran niveles altos de producción de café y que usaran menores proporciones de agua para el lavado de éste, aunque para obtener el mucílago fresco se utilizó por cada 100 libras de café cereza 10 litros de agua y para el fermentado 0.5 litros de agua para 10 libras de café. Se determinó a través de esta técnica que a menor cantidad de agua el mucílago no podía ser desprendido.

Para elaborar etanol se tomaron en cuenta los siguientes aspectos:

Se realizó esterilización de todos los recipientes a utilizar en la experimentación.

Se midió la materia prima y los aditivos: Se utilizaron dos erlenmeyer de 1 litro. El total de materia prima utilizada fueron 20 litros de mucílago fresco y 20 litros de mucílago fermentado, 10 por cada tratamiento ( $1 \mathrm{~L}$ por repetición); además se adicionó el $1 \%$ de levadura (Sacharomyces Cerevisae).

Tratamientos aplicados: Una vez realizada la medición de la materia prima y los aditivos se procedió a realizar los tratamientos, los cuales fueron: Mucílago Fresco sin pasteurizar $+1 \%$ de levadura; Mucílago Fresco Pasteurizado $+1 \%$ de levadura; Mucílago Fermentado sin pasteurizar $+1 \%$ de levadura; Mucílago Fermentado pasteurizado $+1 \%$ de levadura.

El mucílago que se pasteurizaba llegaba a una temperatura de hasta $70^{\circ} \mathrm{C}$. Se enfriaba hasta $30^{\circ} \mathrm{C}$ y se adicionaba la levadura y se procedía al envasado, para llevar a cabo la fermentación por 24 horas, a temperatura ambiente y condiciones anaerobias.

Posteriormente, se realizó una destilación simple, para obtener el alcohol y por último, se hizo la medición de volumen de alcohol obtenido, que consiste en medir el volumen de destilado que se condensó.

\section{Elaboración de abono orgánico}

La metodología empleada en la producción de abono orgánico se basó en la descrito por el Equipo (ECACTAF, 2007). En la formulación se sustituyó el agua por mucílago de café.

Los materiales empleados en la producción del abono orgánico fueron: estiércol $1.5 \mathrm{~kg}$, leguminosas $0.5 \mathrm{~kg}$, Mucílago 20 litros, saco de polipropileno 1, un mecate 1 y una manguera $1 / 2$ pulgada de grosor. La mezcla de producto se dejó fermentar por 15 días, en condiciones anaerobias, para luego proceder a un prensado para eliminar los sólidos gruesos del producto. 
Diseño experimental para el abono orgánico

Se utilizó un diseño completamente al azar (DCA) para la distribución de las unidades experimentales. Se contó con 6 tratamientos con 20 repeticiones por cada uno.

Los datos que se obtuvieron en el periodo de validación del ensilaje, fueron procesados en el uso de un Programa estadístico de Ciencias Sociales (SPSS Statistics, 17.0).

\section{Resultados y discusión}

Una vez aplicada la metodología antes descrita, se presentan los resultados para determinar la opción tecnológica más adecuada para procesar el mucílago del café.

\section{Primer Período de producción de Etanol}

La materia prima de la finca Tisey Estanzuela tenía el mayor de grados Brix (8 y 10), lo que señala que era más efectivo para producir etanol, debido a la cantidad de azúcares que éste presentaba, pero el pH es de 6.1 lo cual no es apropiado para éste experimento, reduciéndolo a 4 mediante la adición de acido cítrico. Según el Investigador Nelson Rodríguez, el pH ideal para este tipo de experimento oscila entre 3.5 y 5.5; además para los grados Brix determinan que estos deben estar en un promedio de 8 a 10 o de concentración de azúcares (Rodríguez, 2009).

La figura 2 muestra de manera global las diferencias existentes por tratamiento aplicado par la variable $\mathrm{ml}$ de alcohol.

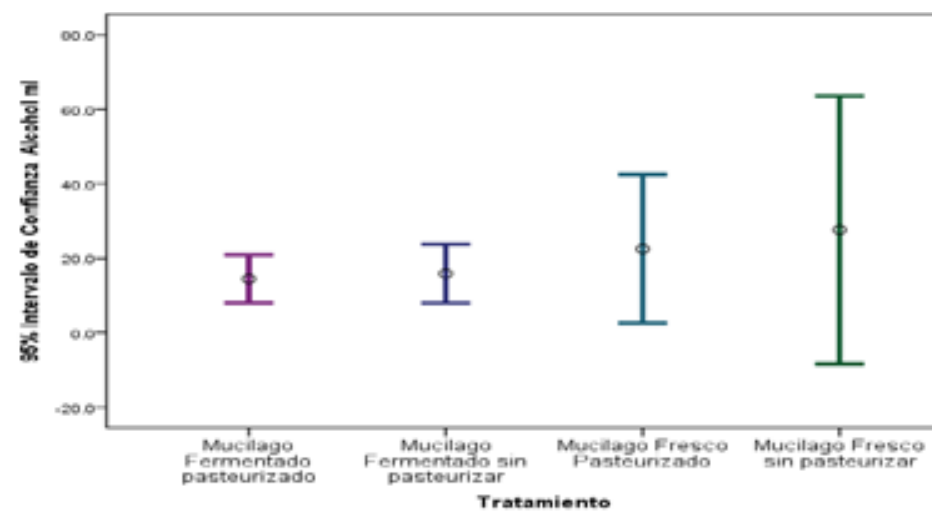

Figura 2. Barra de Error, Diferencias entre $\mathrm{ml}$ de alcohol destilado y tratamientos aplicados.
De manera general, para la variable volumen de alcohol se encontró que no hay diferencia entre los tratamientos $(p=0.603)$. Así mismo en la figura 2 se puede apreciar que los promedios son iguales porque las barras se traslapan. Sin embargo, en los tratamientos mucílago fresco pasteurizado y mucílago fresco sin pasteurizar existe variabilidad en los datos, pero no hay diferencia.

\section{Segundo Período, producción de etanol}

Al igual que en el primer período, se realizaron una serie de procedimientos como la medición del $\mathrm{pH}$ y los grados Brix en el laboratorio de Agroindustria de la Universidad Nacional de Ingeniería.

Las fincas visitadas en esta etapa fueron "El Volcán" y las "Cuevitas" para la recolección de materia prima apropiada para la obtención de Alcohol etílico.

El mucílago fresco y fermentado, tenía 3 a $5{ }^{\circ}$ Brix, respectivamente. Un aspecto relevante de los datos es que resultan ser menores al compararlos con los datos del primer período (8 y 10 Brix).

Un factor que incidió en estas variaciones fue que en el caso de la finca "El Volcán", ubicada en Jinotega, aún cuando las muestras se mantenían en termos con hielo, el proceso de fermentación continuaba, lo que provocaba que la cantidad de azúcar disponible en el producto se disminuyera y en el caso del alcohol producido, éste se degradara a ácidos orgánicos.

En la siguiente figura se muestran los promedios de los cuatro tratamientos en cuanto al contenido de alcohol son iguales estadísticamente.

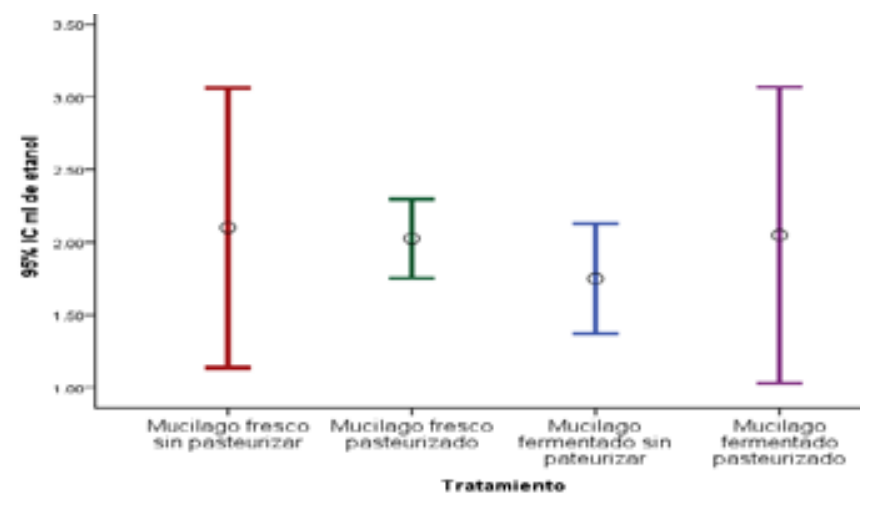

Figura 3. Relación entre los diferentes tipos de tratamientos y $\mathrm{ml}$ de etanol 
A partir de la figura, los tratamientos: Mucílago fresco pasteurizado y mucílago fermentado sin pasteurizar no muestran mucha variación respecto a los datos de los $\mathrm{ml}$ de etanol producido, lo cual indica que los otros dos tratamientos son iguales con alta variación dentro de los tratamientos.

\section{Abono Orgánico}

La cantidad de nitrógeno presente en el abono orgánico es del $0.85 \%$, lo que indica que está en una escala apropiada, pero en el caso del fósforo y potasio el porcentaje es bajo en relación al NPK del purín de estiércol que va de 0.2 al $2 \%$ en general. Este análisis de composición química se llevó a cabo en el Laboratorio Químico S.A. LAQUISA.

De las variables medidas durante el estudio de la validación de abono orgánico a partir de mucílago de café, el peso de la materia seca es la más importante, porque en ésta se denota la asimilación de los nutrientes hacia la planta.

La secuencia de los seis tratamientos que indica la figura 4 nos refleja que el abono químico comercial 1 es el más efectivo, seguidamente el abono comercial 2 y un rango similar está el abono orgánico del $10 \%$ y $30 \%$ teniendo efecto porque es mejor o más pesado que al aplicarle agua y por el último el abono orgánico del $20 \%$ y el testigo, lo que explica que en comparación a los abonos orgánicos comerciales el abono orgánico a partir de mucílago es un inductor de crecimiento para las plantas.

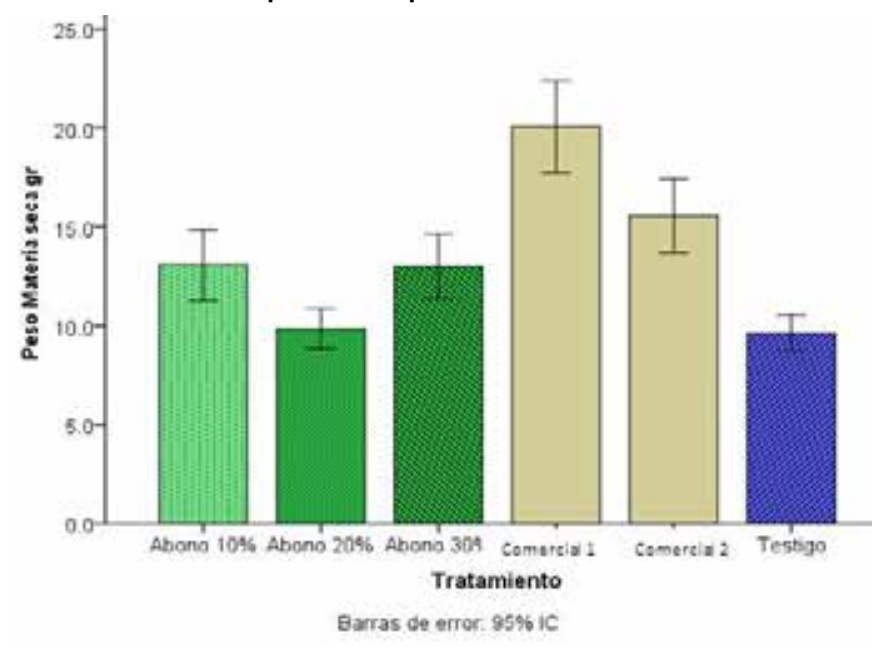

Figura 4. Barra de Error Peso de materia Seca

\section{Costos}

El litro de fertilizante líquido comercial tiene un precio de U\$ 5.15 y durante el ciclo vegetativo del tomate se requerirían 7.1 litros, cuyo costo es de U\$ 36.56. Por lo tanto, producir el abono orgánico resulta más barato, ya que cómo se muestra en la tabla 15, el costo de producción es de U\$25.08, con lo que el productor se ahorraría U\$ 11.54 por ciclo vegetativo en una manzana de plantas de tomate.

\section{Conclusiones}

El rendimiento de alcohol obtenido en el proyecto fue de $2 \%$ en la primera etapa y en la segunda etapa $0.40 \%$, lo que indica que los grados Brix en la primera etapa eran más apropiados para la obtención de etanol ( 8 a $10^{\circ} \mathrm{Bx}$ ) y en la segunda etapa ( 3 a $5^{\circ} \mathrm{Bx}$ ).

El abono orgánico que mejor resultado obtuvo en comparación a los abonos orgánicos comerciales y al testigo fue el del $10 \%$ y $30 \%$.

La producción de abono orgánico tiene un costo menor que el comprar fertilizante líquido comercial y por lo tanto, el productor se ahorraría U\$ 11.54 por ciclo vegetativo en una manzana de plantas de tomate.

\section{Referencias}

ECA-CTAF, E. d. (agosto de 2007). Los abonos orgánicos. Recuperado el 28 de febrero de 2012, de http://es.scribd.com/doc/57039242/abpnpsorganicos

FAO. (2002). Recuperado el 10 de marzo de 2012, de Los Fertilizantes y su Uso: ftp://ftp.fao.org/agl/agll/ docs/fertuso.pdf

Rodríguez, N. (2009). Producción de etanol a partir de los subproductos del café. Recuperado el 24 de septiembre de 2010, de http://www.olade.org/ biocombustibles2009/Documents/ponencias/ ponencias\%20pdf/Sesion\%204\%20-\%20Nelson_ Rodriguez\%20-\%20Colombia.pdf 